\title{
GABA-A and 5-HTIA Receptor Agonists Block Expression of Fear-Potentiated Startle in Mice
}

\author{
Victoria B Risbrough', Jesse D Brodkin ${ }^{3}$ and Mark A Geyer*, 1,2 \\ 'Department of Neurosciences, University of California, San Diego, La Jolla, CA, USA; ${ }^{2}$ Department of Psychiatry, University of California, San \\ Diego, La Jolla, CA, USA; ${ }^{3}$ SIBIA Neurosciences, Inc. (Currently Merck Research Laboratories), San Diego, CA, USA
}

\begin{abstract}
The present experiments characterized the acquisition of fear-potentiated startle (FPS) and determined the sensitivity of FPS to anxiolytic compounds in DBA/IJ mice. A light (30 s) conditioned stimulus (CS) and mild footshock (0.14 mA, $0.5 \mathrm{~s})$ unconditioned stimulus (US) were used. First, acquisition of FPS was examined by presenting the acoustic startle probe during and after each CS-US pairing trial, allowing for a trial-by-trial measurement of experience-dependent startle plasticity. In this novel protocol, mice showed robust acquisition (larger acoustic startle reflex in the presence of the CS) of FPS after as few as eight CS-US pairings. FPS was significantly greater when the CS and US were paired explicitly (light-paired) as compared to when both the US and CS were presented randomly (unpaired), or when the CS was presented alone (no shock), indicating pairing-dependent learning of the CS. Second, the present study assessed the sensitivity of FPS in mice to anxiolytic drugs. The GABA-A receptor agonists diazepam ( 3 and $6 \mathrm{mg} / \mathrm{kg}$ ) and chlordiazepoxide $(10 \mathrm{mg} / \mathrm{kg}$ ) significantly reduced the expression of FPS post-training, as did the serotonin IA receptor partial agonist buspirone $(5 \mathrm{and} I 0 \mathrm{mg} / \mathrm{kg})$ Furthermore, all three anxiolytic drugs reduced startle responding in a cue-specific manner and without significant changes in baseline responding. These data demonstrate a novel method of studying acquisition of FPS, and support the predictive validity of the FPS model of anxiolytic drug action in mice.

Neuropsychopharmacology (2003) 28, 654-663. doi:I 0.I 038/sj.npp. 1300079
\end{abstract}

Keywords: anxiety; fear-potentiated startle; diazepam; chlordiazepoxide; buspirone; mouse

\section{INTRODUCTION}

Recent reports indicate that up to $10 \%$ of the general population suffers from some form of anxiety disorder, and that the 1-year prevalence for all anxiety disorders among adults exceeds $16 \%$ in the United States (Satcher, 1999). The most common pharmacotherapeutics used to treat anxiety have multiple side effects, such as sedation, rapid tolerance, and abuse potential (for a review see Argyropoulos et al, 2000). Hence, the substantial need for improved pharmacotherapy has prompted the search for new drug targets and further characterization of the neural systems underlying anxiety and fear responses (Moldin, 2000; Fendt and Fanselow, 1999; Davis, 1998a; Low et al, 2000; Lang et al, 2000; LeDoux, 2000). The fear-potentiated startle (FPS) model of anticipatory anxiety or fear, first demonstrated by Brown et al (1951) and extensively studied by the Davis laboratory, has been critical to the elucidation of the neural

*Correspondence: Dr MA Geyer, Department of Psychiatry-0804, University of California, San Diego, 9500 Gilman Drive, La Jolla, CA 92093-0804, USA, Tel: + I 619543 3582, Fax: + I 619543 2493, E-mail: mgeyer@ucsd.edu

Received 4 June 2002; revised 23 September 2002; accepted 25 September 2002

Online publication: 3 October 2002 at http://www.acnp.org/citations/ Npp 100302399 circuitry and neurochemistry involved in learned fear behaviors (Davis, 1998b).

FPS is based on classical conditioning engendered by the pairing of a neutral cue (conditioned stimulus - CS) with a noxious stimulus such as electrical shock or air puff (unconditioned stimulus-US). Once the conditioned emotional response has been acquired, the presentation of the cue is considered to elicit a fear- or anxious-like state in the subject (conditioned response). In FPS, this conditioned response is measured operationally by quantifying the reflex response elicited by startling stimuli, with increased startle response magnitudes being observed in the presence of the cue (CS), relative to the absence of the cue.

In humans, the FPS effect has been demonstrated with explicit or instructed conditioning as well as with unconditioned stimuli such as violent images (Spence and Runquist, 1958; Grillon et al, 1991; Bitsios et al, 1999; Hamm et al, 1993). Interestingly, patients with post-traumatic stress disorder and panic disorder exhibit increased startle response magnitudes during baseline or stressful conditions (Butler et al, 1990; Grillon et al, 1994; Morgan et al, 1996; Grillon and Morgan, 1999). Furthermore, adolescents with a familial history of anxiety disorders exhibit increased expression of FPS (Grillon et al, 1998). Taken together, these data support the idea that increased startle reactivity may be a common symptom across different anxiety 
disorders with potentially different pathologies, and that startle reactivity is increased during both anxious and fearrelated states in humans.

The neural circuitry underlying FPS has been investigated extensively in rats and more recently in mice (Brown et al, 1951; Davis, 1992; Falls et al, 1997). For example, FPS in rodents has been clearly linked to the amygdala, with amygdala lesions or intra-amygdala injections of anxiolytic compounds blocking FPS (Davis et al, 1993; Groenink et al, 2000). Imaging studies in humans have revealed that neural systems that are involved in FPS in rodents also appear to be involved in learned fear in humans, supporting the construct validity of the FPS model in rodents (Phelps et al, 2001; LaBar et al, 1998). Furthermore, as in rats, some reports suggest that FPS can be reduced by diazepam administration in humans, showing some parallels between the predictive validity of the FPS model in rats and humans for anxiety treatment (Bitsios et al, 1999; Patrick et al, 1996; but see Baas et al, 2002). FPS has been shown to be a highly predictive model of anxiety in the rat for both anxiolytic and anxiogenic drugs in humans. For example, in rats, clinically effective anxiolytics, such as benzodiazepines and buspirone, block the expression of FPS, while anxiogenics such as yohimbine increase FPS (for a review see Davis et al, 1993). Thus, FPS in rats has proven neurochemical and neural circuitry parallels with anxiety and fear-related behaviors in humans.

Mice are increasingly being used to further examine neural mechanisms underlying complex behaviors through the advent of transgenic technology (eg Gingrich and Hen, 2001). The FPS model in mice may offer substantial benefits in characterizing the mechanisms subserving the acquisition and expression of behaviors related to fear and anxiety. First, the FPS model, unlike typical conflict models of negative affective states, does not measure complex behavior that is modulated by competing drives. Thus, the FPS model may offer enhanced specificity of the interpretation of experimental manipulations without possible motivational (eg Vogel test), approach/avoidance, or locomotor activity confounds (eg elevated plus maze and open field) (Shekhar et al, 2001). This aspect of the FPS model is particularly important when using transgenic mice to describe effects of genes on anxiety-related behaviors, as subtle changes in locomotor activity or approach behavior could confound any putative 'anxiety' phenotype (Dulawa et al, 1999). Second, the model in mice could be used to further characterize the involvement of specific components in the acquisition of fear-related behaviors (eg CREB, Falls et al, 2000) as well as uncover new molecules and mechanisms involved in the expression and extinction of learned fear. Through the work of the Falls laboratory, FPS has been initially characterized in mice and has been shown to be amygdala dependent (Heldt et al, 2000). The next important step is to show that mouse FPS has similar underlying neurochemical systems to human anxiety, that is, shows predictive validity for identifying anxiolytic compounds.

The present study sought to further characterize FPS in mice by (1) determining the acquisition curves for cue- and context-potentiated startle; (2) characterizing the unconditioned effects of the light CS; and (3) determining whether clinically effective anxiolytic drugs reduce the expression of
FPS in mice. Specifically, the effects of buspirone, a serotonin 1A (5-HT1A) receptor partial agonist, and both diazepam and chlordiazepoxide, GABA-A receptor agonists, on FPS were tested in mice. Mice used were of the inbred DBA/1J strain, which has been shown to have moderate-tohigh emotional reactivity in conflict tests relative to other inbred strains, suggesting that these mice may be particularly suited for models of anxiety or fear (Crawley et al, 1997).

\section{METHODS}

\section{Subjects}

Male DBA/1J mice from Jackson Labs (Bar Harbor, Maine), 6-8 weeks of age on arrival, were used for all experiments. Animals were housed four to a cage with food and water provided ad libitum and maintained in a climate-controlled room with a reverse 12-h light/dark cycle (lights on at 17.00). Animals were tested during the dark phase between 10.00 and $16.00 \mathrm{~h}$. Animals were given at least 1 week acclimation to the facility before testing began. Experiments were conducted in accordance with the 'Principles of Laboratory Animal Care' NIH guidelines and with local animal care committee approval.

\section{Apparatus}

Startle chambers (SR-LAB, San Diego Instruments, San Diego, CA) consisted of nonrestrictive Plexiglas cylinders $5 \mathrm{~cm}$ in diameter resting on a Plexiglas platform in a ventilated chamber. High-frequency speakers mounted $33 \mathrm{~cm}$ above the cylinders produced all acoustic stimuli. Scrambled, constant-current footshocks were delivered through a cradle-shaped grid (seven bars with a diameter of $1.6 \mathrm{~mm}$ ) mounted on the floor of the cylinder. Footshocks, startle intensities, and light presentations were controlled by HSR2000 software (SR-LAB). Piezoelectric accelerometers mounted under the cylinders transduced movements of the animal, which were digitized and stored by an interface and computer assembly. Beginning at the startle stimulus onset, 200 consecutive $1 \mathrm{~ms}$ readings were recorded to obtain the peak amplitude of the animals' startle response to either acoustic startle stimuli $(40 \mathrm{~ms})$ or footshock stimuli $(500 \mathrm{~ms})$, respectively. The startle response record window was longer than described previously for mice (in the context of prepulse inhibition experiments; Dulawa and Geyer, 1996) to allow for accurate measurement of peak reactivity to both footshock and startle stimuli. Peak responses to these stimuli are presented in arbitrary units. A dynamic calibration system was used to ensure comparable sensitivities across chambers. Sound levels were measured as described elsewhere (Mansbach and Geyer, 1988) using the A weighting scale in units of dBA SPL. Footshock levels were verified by using a $1 \mathrm{k} \Omega$ resistor across the bars of the shock grids and measuring the voltage drop between the bars to calculate the constant current in milliamperes (mA). The light CS was delivered via a bare $25 \mathrm{~W}$ incandescent bulb located on the ceiling of the testing chamber. A $65 \mathrm{~dB}$ white-noise background was delivered throughout all training and testing sessions. 


\section{Behavioral Testing}

Experiment 1. CS-US pairing-dependent acquisition of FPS in mice

Test session parameters: Experiment 1 utilized a combined training and test session in order to simultaneously establish the classically conditioned response and monitor the acquisition of this response. Accordingly, both CS-US training and startle probes were combined in the same session. Test sessions began with a 5 -min acclimation period followed by $1240-\mathrm{ms} 100-\mathrm{dB}$ startle pulses with an average 15-s (7-23 s range) intertrial interval (ITI) to obtain a baseline measure of startle responding. Two minutes after the baseline period, 30 training trials interspersed with acoustic startle probes were presented. Three groups of mice $(N=12$ each) were trained/tested using three different types of training trials, as illustrated in Figure 1.

Light-paired training trials (Figure 1a): Light-pairing trials (cue trial) consisted of a 30-s light cue in which a $0.14 \mathrm{~mA}$ scrambled footshock was delivered during the last $0.5 \mathrm{~s}$. A dark trial (no-cue trial) lasting between 100 and $240 \mathrm{~s}$ in which there were no-cue or shock presentations immediately followed the light trial. In order to test the acquisition of fear conditioning to the light cue after each pairing, a startle pulse was presented both during the light trial (28.46 s after light onset) and during the dark trial (60$120 \mathrm{~s}$ after light offset). This meant that during each light cue presentation there was a test stimulus (startle probe) as well as the US presentation, thus removing any potential extinction or trace conditioning confounds that may occur when testing FPS acquisition with separate training (CS+US) and testing (CS+startle probe only) trials.
Unpaired training trials (Figure 1b): The light and dark trials were similar to the light-paired group training trials; however, the footshock was presented randomly at any time during either the light or dark trials. Thus, the light cue did not predict the presentation of the footshock. Similarly, the startle probe was presented at a random time interval both during the light trial (1-30 s) and during the dark trial (100240 s). It is important to note that the startle probe was never presented less than $60 \mathrm{~s}$ after a footshock.

No-shock training trials (Figure 1c): Trials were exactly the same as those for the light-paired group except that the footshock presentation was omitted.

Experiment 2. Effects of anxiolytic drugs on expression of FPS. To test the effects of various anxiety-modulating compounds on the expression of FPS, training and subsequent testing sessions were separated by a 24-h period. Drugs were administered only before startle testing. Dose groups for all compounds tested were assigned by counterbalancing baseline (pretraining) startle reactivity and shock reactivity across groups. All drugs were tested in naïve mice 1 day after the initial 20 -trial training session.

Test Session Parameters: Training sessions consisted of a 5 -min acclimation period followed by ten $40-\mathrm{ms} 100-\mathrm{dB}$ startle pulses to record a pretraining startle baseline. After these baseline startle trials, 20 training trials were presented with a 2-min ITI. Training trials consisted of a 30-s light cue with a $0.14 \mathrm{~mA}$ footshock presentation during the last $0.5 \mathrm{~s}$. An unpaired group was also included in the initial diazepam experiment to determine whether the FPS effect was indeed

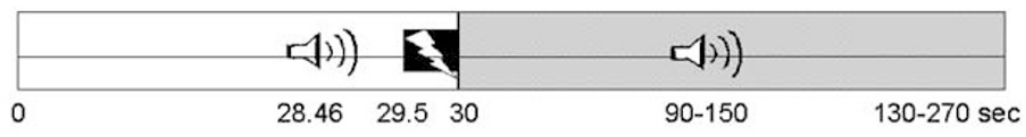

b

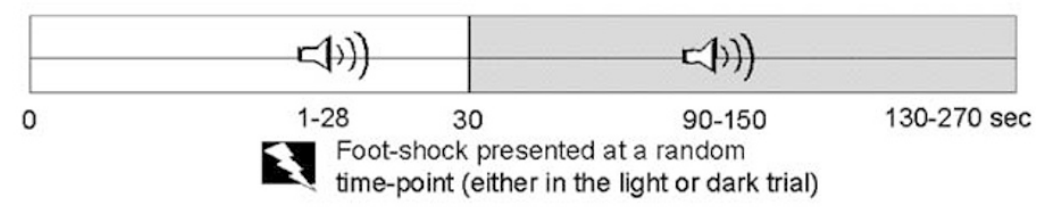

C

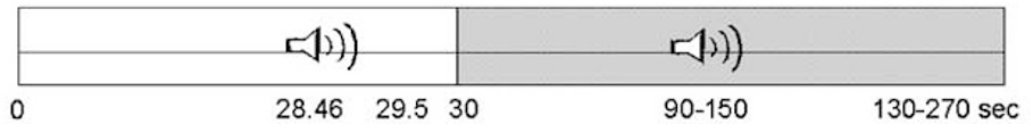

Figure I Schematic description of stimulus presentation during trial-by-trial acquisition protocol. (a) Light-paired training trials. Light trials consisted of a 30 -s light cue in which a $0.14 \mathrm{~mA}$ scrambled footshock was delivered during the last $0.5 \mathrm{~s}$. Dark trials immediately following light trials varied between 100 and $240 \mathrm{~s}$. A startle pulse ( $40 \mathrm{~ms}, 100 \mathrm{~dB}$ ) was presented both $28.46 \mathrm{~s}$ after light onset (light trial) and 60-120 s after footshock (dark trial). (b) Unpaired training trials. The light and dark trials were the same as for the light-paired group training trials with the exception that the footshock was presented randomly at any time during either the light or dark trials. Thus, the light cue did not predict the presentation of the footshock. The startle probe was presented at a random time interval during each light and dark trial. (c) No-shock training trials. Trials were exactly the same as those for the light-paired group except that the footshock presentation was omitted. 
pairing dependent and robust. The unpaired training session consisted of exactly the same session as the initial pairing session except that the footshock was presented randomly during the 2 min ITI.

Test sessions were given $24 \mathrm{~h}$ postconditioning, beginning with a $5 \mathrm{~min}$ acclimation period followed by delivery of 24 total startle pulses $(100 \mathrm{~dB}, 40 \mathrm{~ms}$ in duration) with half of the startle pulses presented during the $30 \mathrm{~s}$ light cue (cue) and the other half without the cue present (ie darkness, nocue). The trials were presented in a pseudorandom order with a 2 -min ITI.

Experiment 3. Effect of chlordiazepoxide on non-CS dependent increases in startle responding. The startle magnitudes in the unpaired and no-shock groups were reassessed 5 days post-training to answer two questions. First, does the potentiated startle in the dark trials observed in the unpaired group remain elevated when no footshocks or light cues are presented? Second, does the same dose of chlordiazepoxide tested in FPS-trained mice (ie cuedependent startle potentiation) reduce the startle potentiation that was not cue dependent (ie context-dependent), or baseline startle responding in mice without fear conditioning (no-shock group)? Therefore, both groups were split, with half receiving vehicle and the other half receiving chlordiazepoxide. The test session consisted of a $65-\mathrm{dB}$ constant background with $20100-\mathrm{dB}$ startle pulses with an average $30 \mathrm{~s}$ ITI. The testing chambers were not lit during the session.

\section{Drugs}

A dose range of 1.0-6.0 mg/kg diazepam (Baxter Healthcare Corp., Deerfield IL) and $10 \mathrm{mg} / \mathrm{kg}$ chlordiazepoxide $\mathrm{HCl}$ (Sigma-Aldrich, St Louis, MO) were dissolved in $0.3 \%$ Tween 80 in $0.9 \%$ sterile saline and administered intraperitoneally in a volume of $10 \mathrm{ml} / \mathrm{kg}$. Buspirone $\mathrm{HCl}$ (SigmaAldrich, St Louis, MO) at a dose range of $2.5-10 \mathrm{mg} / \mathrm{kg}$ was dissolved in $0.9 \%$ sterile saline and administered subcutaneously in a volume of $5 \mathrm{ml} / \mathrm{kg}$. All drugs were administered $30 \mathrm{~min}$ before the testing session.

\section{Data Analysis}

In all experiments, the peak startle magnitude during the record window (eg $200 \mathrm{~ms}$ ) was used for all data analysis. In experiment 1, a three-way ANOVA with repeated measures was utilized, with training type as the between-subject factor and trial type (light 'cue' trial $v s$ dark 'no-cue' trial) and trial number as within-subject factors. To normalize the data to account for differences in startle during the no-cue trials, the percentage of cue potentiation of the startle response over the no-cue startle magnitude (\%FPS) was also calculated for each animal and analyzed separately with training group as a between-subject factor $(\% \mathrm{FPS}=(($ mean 'cue' trial startle magnitude-mean 'no-cue' trial startle magnitude)/mean 'no-cue' trial startle magnitude) $\times 100$ ). When appropriate, simple comparisons and post hoc comparisons were also conducted.

Acquisition data were analyzed by transforming the raw startle values in each pairing trial into a difference score (startle in the light-startle in the dark). The difference score was then transformed to a fraction of the standard deviation of the startle response in the dark for the entire session for each animal ((startle response in light-startle response in dark)/(standard deviation of startle in dark)). This transformation essentially produced a $z$-score for the effect of light on startle amplitude for each mouse at each trial over the session. This data transformation was needed because the inherent variability of startle responding between animals precluded meaningful analysis of the raw difference scores. The data for each training group were then analyzed using a Pearson product moment correlation analysis with number of pairings (ie trial number) and mean difference score (in standard deviation units) as the two variables. For visualization purposes and to assess the relative rates of acquisition across training groups, these data were expressed as a cumulative mean by number of pairings. Separate ANOVA analysis of the cumulative means at each pairing trial was used to assess at which pairing trial the cue-potentiated startle of the light-paired group began to differ significantly from the other training groups. When appropriate, Student-Newman-Keul's post hoc comparisons with training group as the one factor were performed.

In Experiment 2, an ANOVA with drug dose as the between-subject factor and trial type as a within-subject factor was utilized. Drug test session data were also broken into two blocks, Block 1 (first 30 min of session) and Block 2 (second $30 \mathrm{~min}$ of session), to assess extinction of the FPS over testing or change in drug effect over the $1 \mathrm{~h}$ session. Dunnett's post hoc comparisons were used when appropriate. The percentage of FPS was also calculated and analyzed.

\section{RESULTS}

\section{Experiment 1. CS-US Pairing-Dependent Acquisition of} FPS in Mice

Light-paired vs unpaired training. Acoustic startle responses during the light-cue and no-cue conditions were found to be dependent upon training conditions (lightpaired $v s$ unpaired) (Figure 2a) (training $\times$ trial type interaction: $\mathrm{F}(1,22)=5.34, p<0.05$; training: $\mathrm{F}(1,22)<1$, NS; trial type: $\mathrm{F}(1,22)<1$, NS). This interaction is largely because of the light-paired group exhibiting larger startle responses than the unpaired group during the light-cue trials, although this difference did not reach statistical significance in post hoc tests. Indeed, when the raw data are normalized using the percentage FPS (\%FPS), the lightpaired group shows a significantly greater $\%$ FPS than the unpaired group (Figure $2 \mathrm{~b})\left(t_{(22)}=3.27, p<0.01\right)$, again indicating a training-dependent effect on startle responding during the light-cue trials. There was also a main effect of trial number $(\mathrm{F}(1,28)=57.51, p<0.001 ; \mathrm{F}(29,812)=4.48$, $p<0.001$, respectively), which reflects the rapid increase in light and dark startle responding after shock presentations. Surprisingly, when simple post hoc tests were performed to compare light and dark startle responding within each group, there was a significant effect of trial type in the unpaired group as well as the light-paired group (paired$t_{(11)}=2.89, p<0.05$; paired- $t_{(11)}=5.91, p<0.0001$, respectively), indicating that the light cue also facilitates startle 
responding to some degree even in the absence of explicit pairing with the shock stimulus.

Light-paired vs no-shock training. The light-paired group had a significantly greater difference between startle responding in the cue and no-cue trials relative to the noshock group, and also exhibited larger startle responses
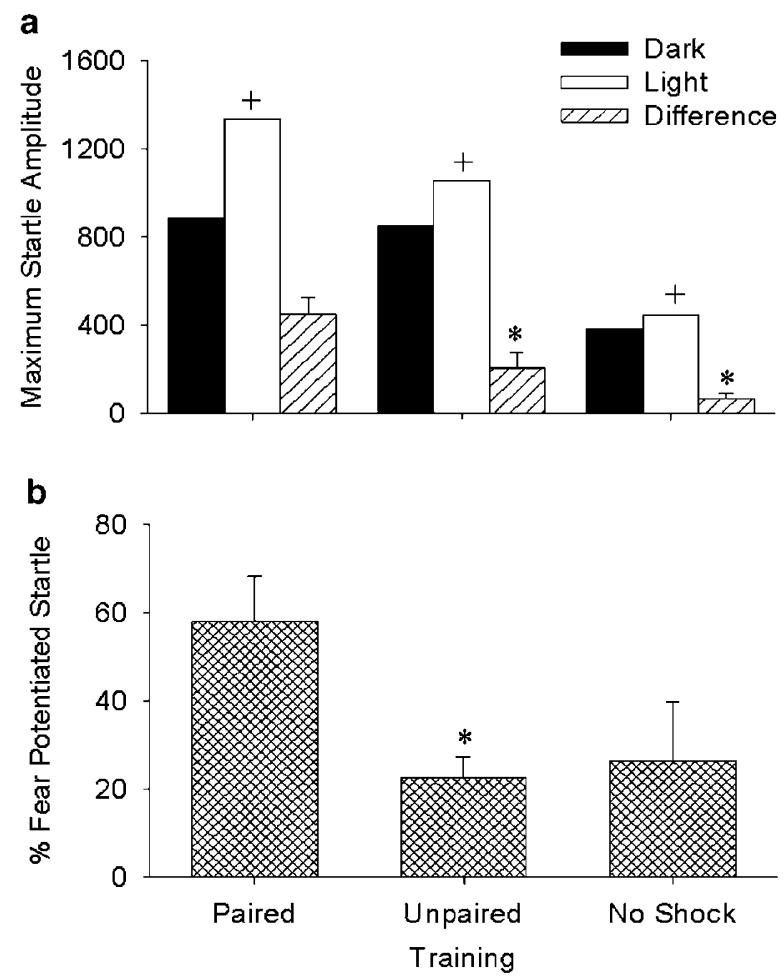

Figure 2 Effect of explicit light-cue/footshock pairing on acoustic startle responding. A light CS (30 s) and footshock US (0.14 mA, $0.5 \mathrm{~s})$ were paired explicitly (light-paired), or randomly presented (unpaired), or the light cue was given alone (no-shock) over 30 training trials. Startle responsiveness was measured with a startle probe presented both during the CS ('light') and during the intertrial interval (ITI, 'dark'). (a) Maximum startle amplitude across light and dark trial types with difference scores (mean light responding-mean dark responding) to illustrate interaction between training and trial type. ${ }^{*} p<0.05$ vs light-paired group, ANOVA training $\times$ trial type interaction. $+p<0.05$ light vs dark responding within each training group, post hoc paired t-test. (b) Percentage of fearpotentiated startle. $* p<0.01$ vs light-paired group, $t$-test. Data are expressed as mean $\pm \mathrm{SEM}, N=12 /$ group overall (Figure 2a) (training $\times$ trial type: $\mathrm{F}(1,22)=21.14$, $p<0.001$; training: $\mathrm{F}(1,22)=85.89, p<0.001)$. Indeed, post hoc analysis revealed that the light-paired training significantly increased startle magnitudes in both the cue and no-cue trials as compared to the no-shock group (Tukey test, $p<0.05)$. The change in overall startle responding is because of the footshock presentations, as can be seen in the overall greater startle magnitudes observed in the unpaired group as well (see Figures $2 \mathrm{~b}$ and 3 ).

An effect of the light cue on startle responding across training groups was also confirmed by a main effect of trial type (trial type: $\mathrm{F}(1,22)=41.90, p<0.001$ ). When the startle responses in the light-cue trials are normalized for no-cue responding, the light-paired group only shows a trend for higher \%FPS in comparison to the no-shock group (Figure 2b) $\left(t_{(22)}=1.97, p=0.06\right)$. Thus, although the data indicate a pairing-dependent increase in startle magnitude in the presence of the cue, the light cue also appears to have some startle-potentiating effects without US pairing.

Analysis of acquisition of potentiated startle. Acquisition data are displayed in Figure 3 (raw startle responses) and Figure 4 (cumulative transformed means). The upward trend in the cumulative mean difference scores as the session progressed suggested that acquisition was occurring in all three training groups (Figure 4). Regression analysis on the raw difference scores (Figure 3), however, revealed a significant correlation between difference scores and number of pairing trials in the light-paired group only (light-paired $r=0.38, p<0.05$; unpaired $r=0.20$, NS; noshock $r=0.24$, NS). To assess the rate of acquisition of FPS across training groups, ANOVAs were run on the cumulative mean at each pairing trial. By the eighth trial, a statistically significant effect of training group was observed $(\mathrm{F}(2,33)=5.192, p<0.05)$, with post hoc analysis indicating that there was a significant difference $(p<0.05)$ between the light-paired and unpaired groups by the eighth pairing trial (Figure 4). This significant difference between the lightpaired and unpaired groups was maintained consistently across all subsequent pairing trials.

Acquisition of context-potentiated startle. During lightcue/footshock pairing, it was also expected that there would be an increase in startle magnitudes in the dark trials relative to pretraining baseline responding, because of conditioned fear elicited by contextual cues. As illustrated

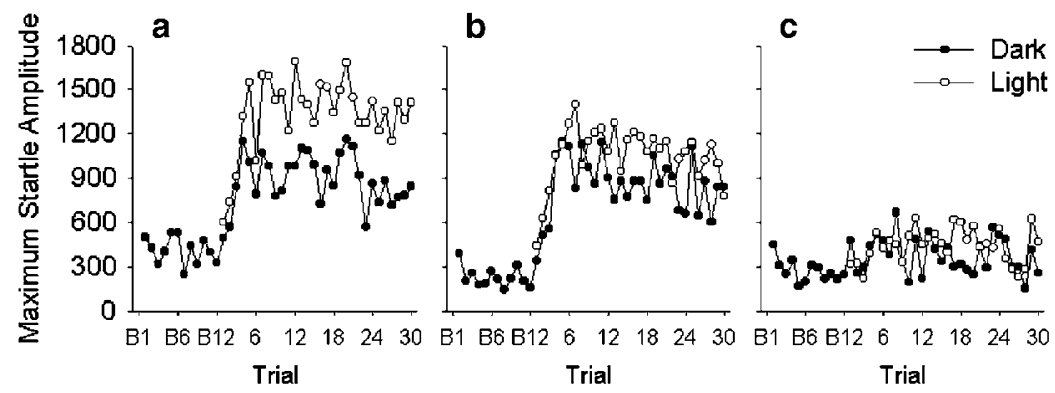

Figure 3 Acquisition of fear-potentiated startle during conditioning (peak startle amplitudes). After I2 baseline acoustic startle probe trials (BI-B I2), 30 pairing trials were presented, with an acoustic startle probe presented during both the cue ('light') and intertrial interval (ITI, 'dark'). (a) Light-paired group: the footshock (US) was presented during the last $0.5 \mathrm{~s}$ of the $30 \mathrm{~s}$ light cue (CS), pooled SEM=54. (b) Unpaired group: the US was presented randomly either during the CS or during the ITI, pooled SEM=50. (c): No-shock group: presentation of the US was omitted, pooled SEM=17, N=12/group. 


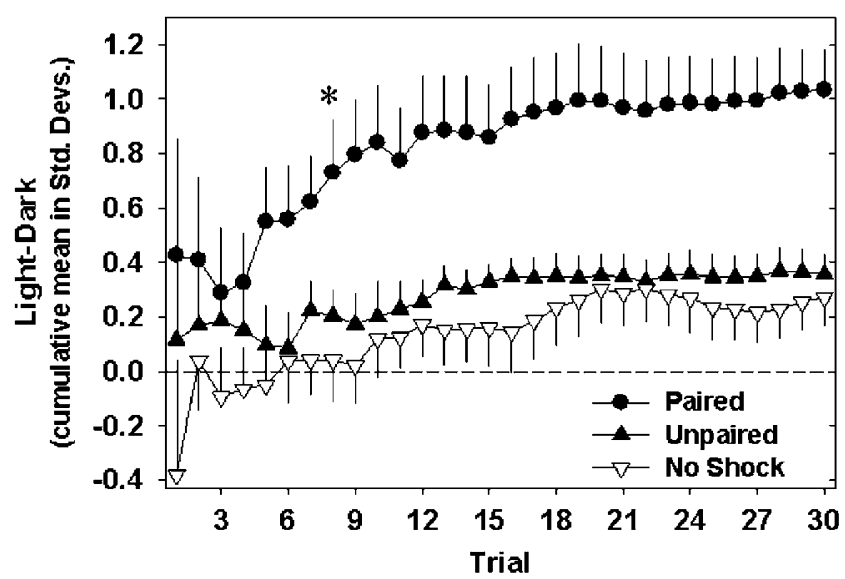

Figure 4 Analysis of acquisition of fear-potentiated startle during conditioning. Data for each animal were calculated by taking the difference between the animal's peak startle amplitude in the light minus the dark (difference score) and then dividing by the standard deviation of the animal's mean startle amplitude in the dark over the entire session. Data are graphed as the cumulative mean \pm SEM by trial for each training group. Light-paired, unpaired, and no-shock groups are denoted by filled circles, filled triangles, and open triangles, respectively. ${ }^{*} p<0.05$ vs unpaired group, Newman-Keul's test. This significant difference between the light-paired and unpaired groups was also maintained consistently across all subsequent pairing trials. $N=12$ /group.

in Figures 3a-c, startle responses in the dark increased above baseline during both unpaired and light-paired training, while the startle response in the dark did not change in the no-shock group. Comparisons of startle responding during baseline and dark trials across the lightpaired, unpaired, and no-shock training groups revealed an interaction between training and dark trial type (dark pretraining baseline $v s$ dark trials during training) (training $\times$ trial type: $\mathrm{F}(2,33)=14.85, p<0.001)$, as well as main effects (training: $\mathrm{F}(2,33)=4.18, p<0.05$; trial type: $\mathrm{F}(1,33)=101.96, p<0.001)$. Post hoc analyses indicated that the light-paired and unpaired groups exhibited significantly larger startle responses in the dark during training compared to the no-shock group (Tukey post hoc test, $p<0.05$ ), while pretraining baseline responding did not differ between the groups.

\section{Experiment 2. Effects of Anxiolytic Drugs on Expression of FPS in Mice}

Light-paired vs unpaired training. Similar to the previous light-paired and unpaired group comparisons, there was a greater difference between startle responses in cue and nocue trials in the light-paired group than the unpaired group (training $\times$ trial type: $\mathrm{F}(1,11)=5.88, p<0.05$ ), although post $h o c$ analysis did not reveal a significant difference between the two groups on cue-trial responding specifically (lightpaired: cue $=1269 \pm 162$, no-cue $=779 \pm 136$; unpaired: cue $=921 \pm 255$, no-cue $=799 \pm 225$ ). The light-paired group also showed significantly greater \%FPS than the unpaired group (mean \%FPS: light-paired $=71.6 \pm 16.9$, unpaired $=17.1 \pm 13.7)\left(t_{(11)}=2.23, p<0.05\right)$.

There was also a main effect of trial type, again perhaps indicating some pairing-independent potentiation by the
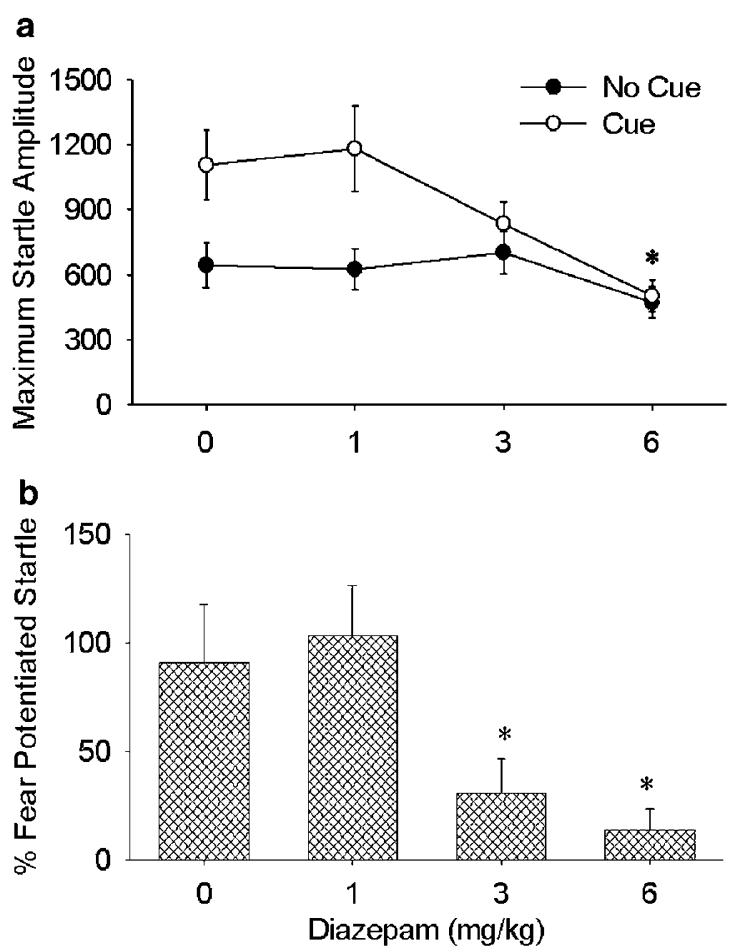

Figure 5 Effect of the GABA-A receptor agonist diazepam (I, 3, 6 mg/ $\mathrm{kg}$ ) administration on fear-potentiated startle in mice $24 \mathrm{~h}$ postconditioning. (a) Maximum startle amplitude responses with (cue) and without (no-cue) the presentation of the light cue. (b) Percentage of fear-potentiated startle. * $p<0.05$ vs vehicle, Dunnett's test. Data are expressed as mean \pm SEM, $N=9-15 /$ group.

light cue, but no main effects of training or block (trial type: $\mathrm{F}(1,11)=16.36, p<0.01$; training: $\mathrm{F}(1,11)<1$, NS; block: $\mathrm{F}(1,11)=1.41, \mathrm{NS})$.

Diazepam. Diazepam administration significantly reduced startle potentiation in the presence of the cue without affecting startle magnitude in the no-cue trials (Figure 5a) (trial type $\times$ drug: $\mathrm{F}(3,47)=2.95, p<0.05$; drug: $\mathrm{F}(3,47)=$ 1.85 , NS; trial type: $\mathrm{F}(1,47)=28.82, p<0.0001)$. There was also a significant interaction between drug, trial type, and block $(\mathrm{F}(3,47)=5.08, p<0.005)$ and between block and trial type $(\mathrm{F}(1,47)=4.25, p<0.05)$. This interaction was due mainly to a significant decrease in the effect of the cue on potentiated startle in the vehicle group during block 2, indicating that there was extinction of the fear potentiation over the session. Therefore, only data from block 1, where FPS is most robust, are shown and analyzed further (Figure 5). Post hoc one-way ANOVAs on each trial type during block 1 revealed no effect of drug on no-cue trials $(\mathrm{F}(3,47)<1$, NS) but did reveal a significant effect of dose on cue trials $(\mathrm{F}(3,47)=3.39, p<0.05)$. The $6 \mathrm{mg} / \mathrm{kg}$ dose group had significantly lower startle responses during the cue trials as compared to the vehicle group (Figure 5a) $(p<0.05$, Dunnett's test). The percentage of FPS was also significantly reduced in the diazepam-treated group (drug: $\mathrm{F}(3,47)=4.88, p<0.005)$, with post hoc analysis revealing a significant reduction in both the 3 and $6 \mathrm{mg} / \mathrm{kg}$ dose groups as compared to the vehicle group (Figure 5b) (Dunnett's test, $p<0.05)$. 
Chlordiazepoxide. Chlordiazepoxide had a strong trend to decrease cue potentiated startle without affecting startle responding during no-cue trials (Figure 6a) (trial type$\times$ drug: $\mathrm{F}(1,10)=4.24, p=0.067$; drug: $\mathrm{F}(1,10)=1.29$, NS; trial type: $\mathrm{F}(1,10)=20.08, p<0.01)$. There was a main effect of block $(\mathrm{F}(1,10)=8.44, p<0.05)$; however there were no interactions with drug treatment or trial type $(\mathrm{F}(1,10)<1.0$, NS). The block effect was because of an overall decrease in startle magnitude in block 2 that was seen across both drug group and trial conditions; hence, the data were collapsed to be graphed and analyzed across the entire testing session (Figure 6). Chlordiazepoxide also significantly reduced $\%$ FPS (Figure $6 \mathrm{~b})\left(t_{(10)}=1.87, p<0.05\right)$.

Buspirone. As hypothesized, the 5-HT1A partial agonist buspirone had a significant effect on startle magnitude that was trial-type dependent (Figure 7a) (trial type $\times$ drug: $\mathrm{F}(3,37)=3.48, p<0.05$; drug: $\mathrm{F}(3,37)=1.23$, NS). A main effect of trial type was also found, with the cue trials eliciting much greater startle magnitudes than the no-cue trials $(F(1,37)=64.98, p<0.001)$. Since there were no main effects of block $(\mathrm{F}(1,37)<1, \mathrm{NS})$ or interactions with trial type or drug treatment $(\mathrm{F}(3,37)<1$, NS), the data were collapsed across the entire testing session. One-way ANOVAs of drug effects on cue and no-cue trials separately did not reveal a drug effect on either trial type alone $(F(3,37)=1.48$; NS; $F(3,37)=1.18$, NS, respectively $)$. The percentage of FPS, however, was significantly reduced by buspirone administration $(\mathrm{F}(3,37)=6.02, p<0.002)$, with both the 5 and $10 \mathrm{mg} / \mathrm{kg}$ doses significantly decreasing $\%$ FPS compared to the vehicle group (Figure 7b) (Dunnett's test $p<0.05)$.

\section{Experiment 3. Effect of Chlordiazepoxide on Non-CS Dependent Increases in Startle Responding}

To test whether the increased startle amplitude during shock presentations is because of shock sensitization and/or contextual learning, the unpaired and no-shock groups from experiment 1 were retested with dark trials only (noshock presentations) 5 days post-training. The unpaired group continued to exhibit larger startle responses relative to the no-shock group; however this difference diminished as the testing session progressed, as revealed by a main effect of training and a training by trial number interaction (Figure 8) (training: $\mathrm{F}(1,26)=11.38, p<0.01$; training $\times$ trial number: $F(9,234)=2.82, p<0.01)$. Neither group was affected by chlordiazepoxide $(10 \mathrm{mg} / \mathrm{kg}$ ) treatment (drug: $\mathrm{F}(1,26)<1$, NS; drug $\times$ training: $\mathrm{F}(1,26)<1, \mathrm{NS})$.
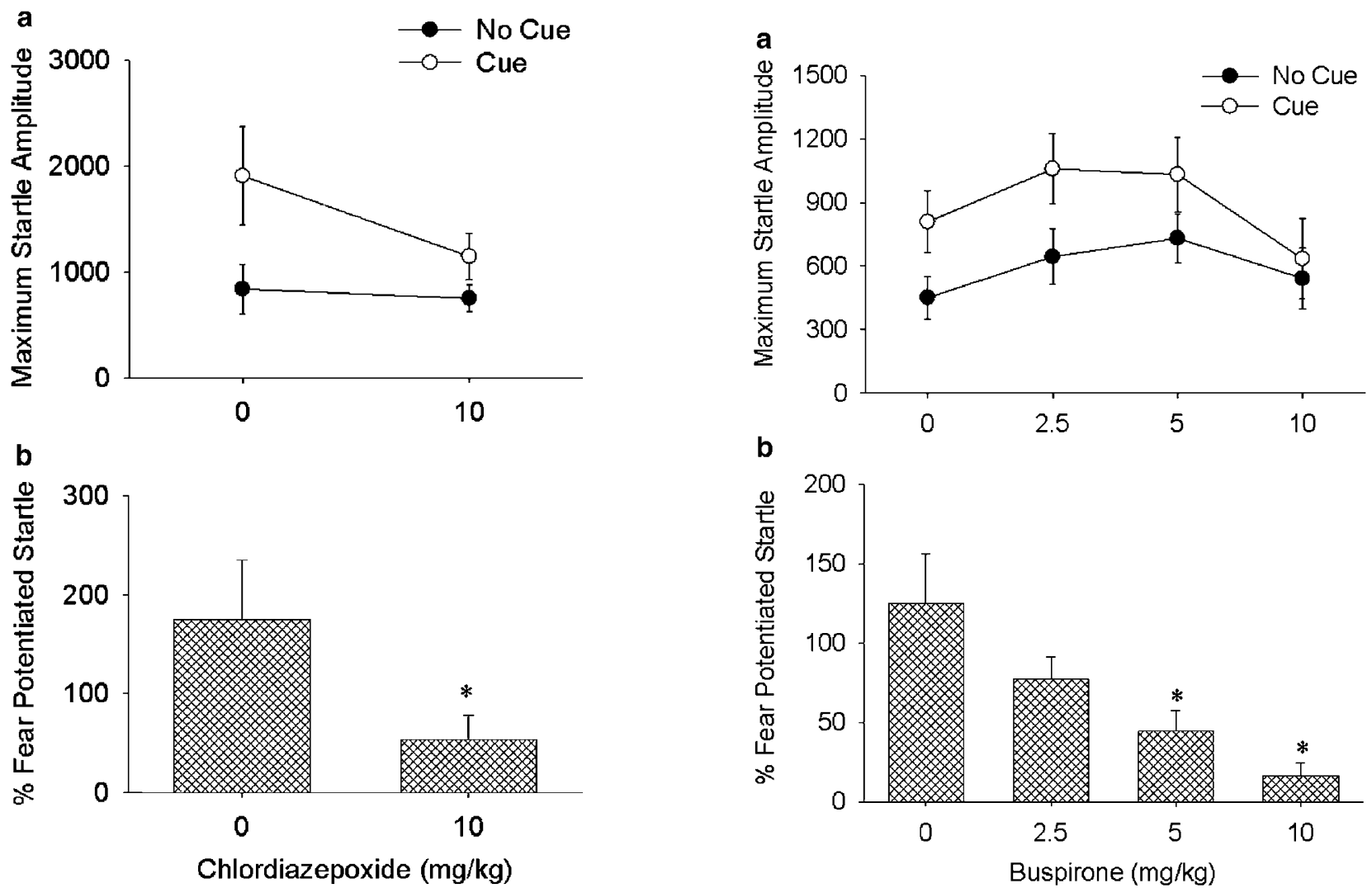

b

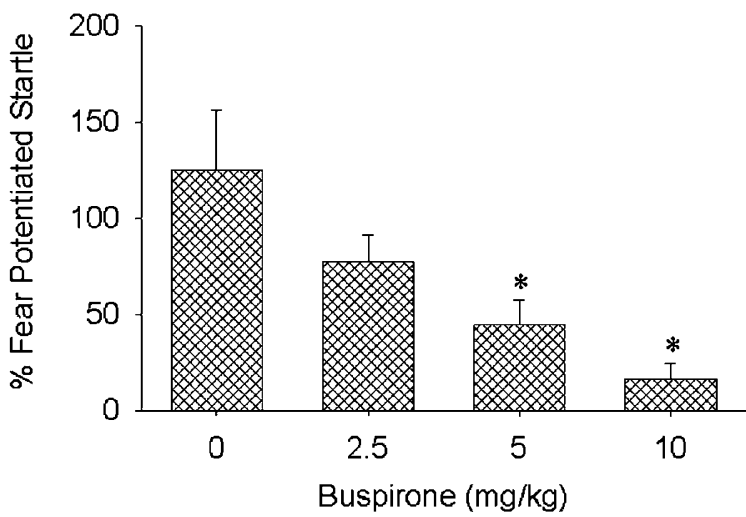

Figure 6 Effect of the GABA-A receptor agonist chlordiazepoxide $(10 \mathrm{mg} / \mathrm{kg})$ administration on fear-potentiated startle in mice $24 \mathrm{~h}$ postconditioning. (a) Maximum startle amplitude responses with (cue) and without (no-cue) the presentation of the light cue. (b) Percentage of fear-potentiated startle. ${ }^{*} p<0.05$ vs vehicle, Dunnett's test. Data are expressed as mean $\pm \mathrm{SEM}, \mathrm{N}=6$ /group.

Figure 7 Effect of 5-HTIA receptor partial agonist buspirone $(2.5,5$, $10 \mathrm{mg} / \mathrm{kg}$ ) administration on fear-potentiated startle in mice $24 \mathrm{~h}$ postconditioning. (a) Maximum startle amplitude responses with (cue) and without (no-cue) the presentation of the light cue. (b) Percentage of fear-potentiated startle. ${ }^{*} p<0.05$ vs vehicle, Dunnett's test. Data are expressed as mean \pm SEM, $N=9-1$ I/group. 


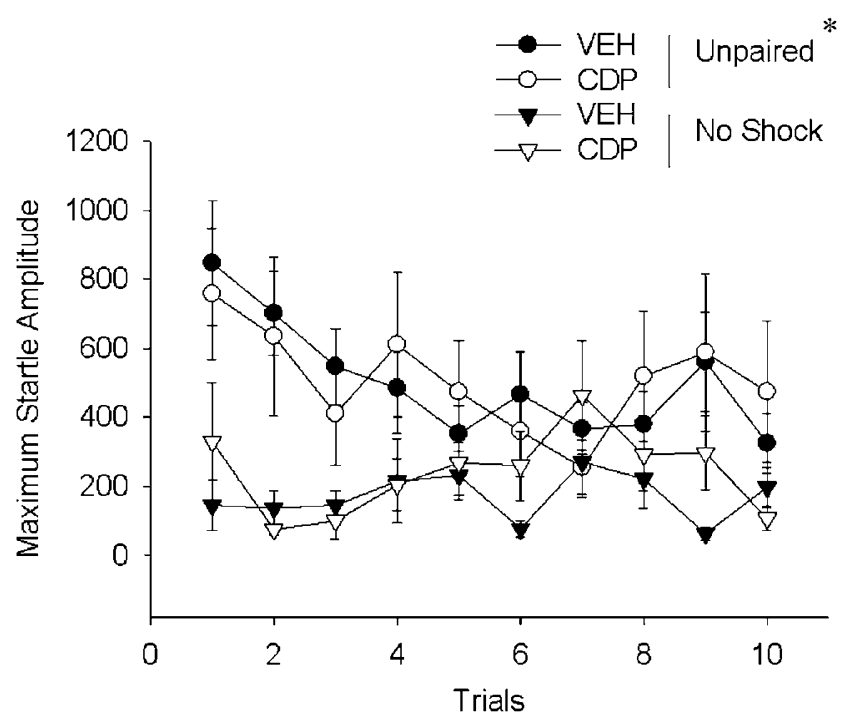

Figure 8 Effect of the GABA-A receptor agonist chlordiazepoxide $(10 \mathrm{mg} / \mathrm{kg})$ administration on context-potentiated startle. Maximum startle amplitudes were recorded in unpaired and no-shock groups 5 days posttraining (see Figures I and 2), 30 min after chlordiazepoxide or vehicle treatment. Data are expressed as mean \pm SEM. ${ }^{*} p<0.01$ main effect of training, two-way ANOVA. N=6-9/group.

\section{DISCUSSION}

The present study showed that FPS engendered by pairing a light cue with a mild footshock is robustly acquired over a relatively small number of trials in male DBA/1J mice. Additionally, a slight but significant pairing-independent effect of light on startle responding was observed. The clinically effective anxiolytic drugs, diazepam, chlordiazepoxide, and buspirone, significantly reduced FPS without producing significant changes in baseline startle responding.

The acquisition of FPS was studied on a trial-by-trial basis to characterize the acquisition curve for FPS in DBA/1J mice. This type of protocol could be particularly valuable for characterizing anxiety-like phenotypes in mice with constitutive genetic manipulations to help dissociate the acquisition from the expression and extinction of FPS (ie is an anxious-like phenotype because of exaggerated expression or accelerated learning of fear conditioning?). This particular protocol was also designed to avoid any confounds associated with the inclusion of unpaired cue presentations (ie extinction trials) when training and testing trials are separated, as in previous similar protocols (Walker and Davis, 2000; Kim and Davis, 1993; Heldt et al, 2000). The observed acquisition curve for light-cue potentiated startle in this strain of mouse was very rapid. This finding was somewhat surprising because previous studies using light as the CS for FPS indicated that up to 60 trials are needed in C57BL/6J mice, and up to 10-15 trials are needed in rats (Heldt et al, 2000; Mansbach and Geyer, 1988). In the present study, statistically significant FPS in DBA/1J mice appeared by eight pairing trials during the combined acquisition/testing session. C57BL/6J mice, however, when trained with the same protocol as described in the present study ( 20 trials $24 \mathrm{~h}$ pretest), do not acquire FPS (unpublished observations), indicating that there are large differences in acquisition of FPS across mouse strains. DBA/ 1J mice have been shown to have moderate-to-high emotional reactivity in conflict tests in comparison to other strains, and the relatively similar DBA/2J strain also appears to express FPS more robustly than the C57BL/6J strain (Crawley et al, 1997; Falls et al, 1997; McCaughran et al, 2000). Indeed, McCaughran et al (2000) reported that DBA/ 2J mice but not C57BL/6J mice learned FPS and that robust acquisition of the FPS is a highly heritable trait in subsequent intercrossed generations. Interestingly, fear conditioning as measured by freezing can be acquired after a single trial in C57BL/6J mice, indicating that there may be some differences in the underlying systems involved in conditioned freezing and potentiated startle (Stiedl et al, 2000; see also McNish et al, 1997).

A more detailed examination of the acquisition data for all training groups showed a positive correlation between the number of pairing trials and the difference in startle amplitude in the light $v s$ the dark. This positive correlation suggests that the effect of the light on startle amplitude increased over the length of the training session and implies that there was an experience-dependent effect on startle responding, that is, learning. Conversely, if the difference were innate or unconditioned, one would expect that the trial-type specific pattern of responding would not show any correlation with experience. Although the correlation between the number of pairing trials and the difference in responding between cue and no-cue trials was statistically significant only in the light-paired group, both the unpaired and no-shock groups showed trends for positive correlations as well. Hence, it would be premature to dismiss the possibility that a component of the difference between startle amplitude in the light $v s$ the dark trial may be innate. Moreover, although not statistically significant, the positive correlation observed in the unpaired and no-shock group raises the intriguing possibility that the startle-potentiating effects of light in this and previous studies (Heldt et al, 2000) may be the result of a learned association (ie the startle-eliciting stimulus functioning as the US and the light functioning as the CS for fear conditioning). This was not expected however, as the startle stimulus is presented both during light and dark trials, and thus neither the light nor dark would be solely predictive of the 'US' (startle stimulus). It is possible however that the salience of the light stimulus as compared to the dark trial was great enough to engender a conditioned response after repeated pairing with the aversive startle stimulus. This hypothesis might explain why the no-shock group failed to show any light potentiation of startle until more than 10 pairings of the light and noise had occurred (Figure 4). This explanation is also consistent with the study by Leaton and Cranney (1990), which suggested that a startle-eliciting stimulus could function as a US for fear conditioning in rats. Further experiments examining the effect of previous pairings of light and noise on light-potentiated startle are required to fully address this hypothesis.

The present finding of an increase in startle responding in the light that is independent of pairings with a US, also coincides with previous reports of the light-enhanced startle' (LES) effect in both rats and mice (Ison and Hammond, 1971; Heldt et al, 2000). In rats, LES is blocked by systemic administration of anxiolytic drugs or by 
infusions of glutamate antagonists into either the bed nucleus of the stria terminalis (BNST) or the basolateral nucleus of the amygdala, suggesting that fear or an anxiouslike state may be a component of LES (Walker and Davis, 1997; de Jongh et al, 2002). In C57BL/6J mice however, LES was not blocked by amygdala lesions (Heldt et al, 2000). It thus remains to be seen whether the BNST, which may have a direct connection to the nucleus reticularis pontis caudalis, an area critical for startle, may mediate LES in mice.

Another characteristic of FPS in the present study was the progressive increase in startle reactivity during the dark ITI in both the light-paired and unpaired groups during the initial 4-5 trials (Figure 3), which may be attributable to conditioning to contextual cues (ie the startle chamber). This hypothesis is supported by the data gathered 5 days post-training in the absence of any further shock presentations (Figure 8). In this test, startle magnitudes were elevated significantly above pretraining levels in the unpaired group, with similar initial startle responding as was observed during training (Figure 3), and gradually returned to baseline levels when testing was repeated without shock presentations (ie probable extinction). This behavioral pattern suggests that the increased startle in the unpaired group observed during the testing session is likely a reflection of learned fear elicited by the testing chamber serving as a contextual cue and not the consequence of immediate sensitization of startle responses that may be occurring in the training session (for a further discussion of shock-induced sensitization, see Davis, 1989 and Richardson, 2000) as no shocks were presented in the testing session.

The present study is the first report, to our knowledge, of the blockade of FPS in mice by the administration of clinically effective anxiolytics. The benzodiazepine GABA-A receptor agonists diazepam ( 3 and $6 \mathrm{mg} / \mathrm{kg}$ ) and chlordiazepoxide $(10 \mathrm{mg} / \mathrm{kg})$ blocked FPS without significantly reducing startle responding when the cue was not present. This result contrasts with the effects of benzodiazepines on FPS in rats, in which benzodiazepines are reported to decrease both cue-potentiated and baseline no-cue startle when training and testing occur in the same apparatus (Guscott et al, 2000). It may be that higher doses are needed in mice to reduce the startle potentiation in the dark because of context conditioning. Indeed, in the present study, the $10 \mathrm{mg} / \mathrm{kg}$ dose of chlordiazepoxide had no effect on the context-potentiated startle responding in the unpaired group, which may indicate that a higher dose of chlordiazepoxide is needed to block context-potentiated startle than is effective for FPS. It is also important to note that the effective doses of diazepam and chlordiazepoxide are similar to the effective dose range of these compounds in the elevated plus maze in mice, indicating some commonality across benzodiazepine dose ranges for the FPS model and other models of anxiety in mice (Lister, 1987; Griebel et al, 2000).

The present study is also the first to report the blockade of FPS in mice by administration of the serotonin 1A receptor partial agonist buspirone. Buspirone did, however, appear to increase startle responding independent of trial conditions at the lower doses, although this difference was not significant. The effective doses of buspirone in the present study are also similar to those reported in rats for FPS, as is the slight increase in overall startle responding (Mansbach and Geyer, 1988). The neural site of anxiolytic action of buspirone and other 5-HT1A agonists is somewhat unclear (Menard and Treit, 1999). In rats, lesions of both the septum and raphe nucleus, areas with extensive 5-HT1A receptor distributions, failed to block the effect of buspirone on FPS (Melia and Davis, 1991; Davis et al, 1988). Administration of the 5-HT1A receptor full agonist flesinoxan into the amygdala, but not the raphe nuclei, blocked FPS in rats, suggesting that some of the effects of 5HT1A activation on FPS may be mediated via the amygdala (Groenink et al, 2000).

Although the site of action of the anxiolytics tested in mouse FPS is currently unknown, the present data provide strong initial evidence for the predictive validity of the FPS model for identifying anxiolytic treatments in mice. Further studies of the modulation of FPS in mice by anxiogenic compounds and nonanxiolytic compounds are now required to further characterize the predictive validity of FPS in mice as a model of anxiety.

\section{ACKNOWLEDGEMENTS}

These studies were supported by a grant from the National Institute on Drug Abuse (DA02925), the MERCK NEP fellowship and by the Veterans Affairs VISN 22 Mental Illness Research, Education, and Clinical Center. We thank Richard Sharp and Jonathon Stroebel for their excellent technical assistance. We thank Dr Susan Powell for her helpful comments during these studies and in the writing of this manuscript. MA Geyer holds an equity interest in San Diego Instruments.

\section{REFERENCES}

Argyropoulos SV, Sandford JJ, Nutt DJ (2000). The psychobiology of anxiolytic drugs. Part 2: pharmacological treatments of anxiety. Pharmacol Ther 88: 213-27.

Baas JM, Grillon C, Bocker KB, Brack AA, Morgan CA, Kenemans JL et al (2002). Benzodiazepines have no effect on fearpotentiated startle in humans. Psychopharmacology 161: 233-47.

Bitsios P, Philpott A, Langley RW, Bradshaw CM, Szabadi E (1999). Comparison of the effects of diazepam on the fear-potentiated startle reflex and the fear-inhibited light reflex in man. $J$ Psychopharmacol 13: 226-34.

Brown JS, Kalish HI, Farber IE (1951). Conditional fear as revealed by magnitude of startle response to an auditory stimulus. J Exp Psychol 41: 317-328.

Butler RW, Braff DL, Rausch JL, Jenkins MA, Sprock J, Geyer MA (1990). Physiological evidence of exaggerated startle response in a subgroup of Vietnam veterans combat-related PTSD. Am J Psychiatry 147: 1308-12.

Crawley JN, Belknap JK, Collins A, Crabbe JC, Frankel W, Henderson $\mathrm{N}$ et al (1997). Behavioral phenotypes of inbred mouse strains: implications and recommendations for molecular studies. Psychopharmacology 132: 107-24.

Davis M (1989). Sensitization of the acoustic startle reflex by footshock. Behav Neurosci 103: 495-503.

Davis M (1992). The role of the amygdala in fear and anxiety. Annu Rev Neurosci 15: 353-75.

Davis M (1998a). Are different parts of the extended amygdala involved in fear versus anxiety? Biol Psychiatry 44: 1239-47. 
Davis M (1998b). Anatomic and physiologic substrates of emotion in an animal model. J Clin Neurophysiol 15: 378-87.

Davis M, Cassella JV, Kehne JH (1988). Serotonin does not mediate anxiolytic effects of buspirone in the fear-potentiated startle paradigm: comparison with 8-OH-DPAT and ipsapirone. Psychopharmacology 94: 14-20.

Davis M, Falls WA, Campeau S, Kim M (1993). Fear-potentiated startle: a neural and pharmacological analysis. Behav Brain Res 58: $175-98$.

de Jongh R, Groenink L, van Der Gugten J, Olivier B (2002). The light-enhanced startle paradigm as a putative animal model for anxiety: effects of chlordiazepoxide, flesinoxan and fluvoxamine. Psychopharmacology 159: 176-80.

Dulawa SC, Geyer MA (1996). Psychopharmacology of prepulse inhibition in mice. Chin J Physiol 39: 139-46.

Dulawa SC, Grandy DK, Low MJ, Paulus MP, Geyer MA (1999). Dopamine D4 receptor-knockout mice exhibit reduced exploration of novel stimuli. J Neurosci 19: 9550-9556.

Falls WA, Carlson S, Turner JG, Willott JF (1997). Fear-potentiated startle in two strains of inbred mice. Behav Neurosci 111: 855-61.

Falls WA, Kogan JH, Silva AJ, Willott JF, Carlson S, Turner JG (2000). Fear-potentiated startle, but not prepulse inhibition of startle, is impaired in CREBalphadelta-I- mutant mice. Behav Neurosci 114: 998-1004.

Fendt M, Fanselow MS (1999). The neuroanatomical and neurochemical basis of conditioned fear. Neurosci Biobehav Rev 23: 743-60.

Gingrich JA, Hen R (2001). Dissecting the role of the serotonin system in neuropsychiatric disorders using knockout mice. Psychopharmacology 155: 1-10.

Griebel G, Belzung C, Perrault G, Sanger DJ (2000). Differences in anxiety-related behaviours and in sensitivity to diazepam in inbred and outbred strains of mice. Psychopharmacology 148: 164-70.

Grillon C, Ameli R, Goddard A, Woods SW, Davis M (1994). Baseline and fear-potentiated startle in panic disorder patients. Biol Psychiatry 35: 431-9.

Grillon C, Ameli R, Woods SW, Merikangas K, Davis M (1991). Fear-potentiated startle in humans: effects of anticipatory anxiety on the acoustic blink reflex. Psychophysiology 28: 588-95.

Grillon C, Dierker L, Merikangas KR (1998). Fear-potentiated startle in adolescent offspring of parents with anxiety disorders. Biol Psychiatry 44: 990-7.

Grillon C, Morgan III CA (1999). Fear-potentiated startle conditioning to explicit and contextual cues in Gulf War veterans with posttraumatic stress disorder. J Abnorm Psychol 108: $134-42$.

Groenink L, Joordens RJ, Hijzen TH, Dirks A, Olivier B (2000). Infusion of flesinoxan into the amygdala blocks the fearpotentiated startle. Neuroreport 11: 2285-8.

Guscott MR, Cook GP, Bristow LJ (2000). Contextual fear conditioning and baseline startle responses in the rat fearpotentiated startle test: a comparison of benzodiazepine/gammaaminobutyric acid-A receptor agonists. Behav Pharmacol 11: 495-504.

Hamm AO, Greenwald MK, Bradley MM, Lang PJ (1993). Emotional learning, hedonic change, and the startle probe. $J$ Abnorm Psychol 102: 453-65.

Heldt S, Sundin V, Willott JF, Falls WA (2000). Posttraining lesions of the amygdala interfere with fear-potentiated startle to both visual and auditory conditioned stimuli in C57BL/6J mice. Behav Neurosci 114: 749-59.

Ison JR, Hammond GR (1971). Modification of the startle reflex in the rat by changes in the auditory and visual environments. $J$ Comp Physiol Psychol 75: 435-52.

Kim M, Davis M (1993). Electrolytic lesions of the amygdala block acquisition and expression of fear-potentiated startle even with extensive training but do not prevent reacquisition. Behav Neurosci 107: 580-595.

LaBar KS, Gatenby JC, Gore JC, LeDoux JE, Phelps EA (1998). Human amygdala activation during conditioned fear acquisition and extinction: a mixed-trial fMRI study. Neuron 20: 937-45.

Lang PJ, Davis M, Ohman A (2000). Fear and anxiety: animal models and human cognitive psychophysiology. J Affect Disord 61: 137-59.

Leaton RN, Cranney J (1990). Potentiation of the acoustic startle response by a conditioned stimulus paired with acoustic startle stimulus. J Exp Psychol 16: 279-287.

LeDoux J (2000). Emotion circuits in the brain. Annu Rev Neurosci 23: $155-184$

Lister RG (1987). The use of a plus-maze to measure anxiety in the mouse. Psychopharmacology 92: 180-5.

Low K, Crestani F, Keist R, Benke D, Brunig I, Benson JA et al (2000). Molecular and neuronal substrate for the selective attenuation of anxiety. Science 290: 131-4.

Mansbach RS, Geyer MA (1988). Blockade of potentiated startle responding in rats by 5 -hydroxytryptamine1A receptor ligands. Eur J Pharmacol 156: 375-83.

McCaughran Jr JA, Bell J, Hitzemann III RJ (2000). Fearpotentiated startle response in mice: genetic analysis of the C57BL/6J and DBA/2J intercross. Pharmacol Biochem Behav 65: 301-12.

McNish KA, Gewirtz JC, Davis M (1997). Evidence of contextual fear after lesions of the hippocampus: a disruption of freezing but not fear-potentiated startle. J Neurosci 17: 9353-9360.

Melia KR, Davis M (1991). Effects of septal lesions on fearpotentiated startle, and on the anxiolytic effects of buspirone and diazepam. Physiol Behav 49: 603-11.

Menard J, Treit D (1999). Effects of centrally administered anxiolytic compounds in animal models of anxiety. Neurosci Biobehav Rev 23: 591-613.

Moldin S (2000). Neurobiology of anxiety and fear: challenges for genomic science of the new millennium. Biol Psychiatry 48: 1144-1146.

Morgan III CA, Grillon C, Southwick SM, Davis M, Charney DS (1996). Exaggerated acoustic startle reflex in Gulf War veterans with posttraumatic stress disorder. Am J Psychiatry 153: 64-8.

Patrick CJ, Berthot BD, Moore JD (1996). Diazepam blocks fearpotentiated startle in humans. J Abnorm Psychol 105: 89-96.

Phelps EA, O'Connor KJ, Gatenby JC, Gore JC, Grillon C, Davis M (2001). Activation of the left amygdala to a cognitive representation of fear. Nat Neurosci 4: 437-41.

Richardson R (2000). Shock sensitization of startle: learned or unlearned fear? Behav Brain Res 110: 109-17.

Satcher D (1999). In: Goldman HH, Rye P, Sirovatka P (eds). US Mental Health: A Report of the Surgeon General. US Department of Health and Human Services: Rockville.

Shekhar A, McCann UD, Meaney MJ, Blanchard DC, Davis M, Frey KA et al (2001). Summary of a National Institute of Mental Health workshop: developing animal models of anxiety disorders. Psychopharmacology 157: 327-39.

Spence KW, Runquist WN (1958). Temporal effects of conditioned fear on the eyelid reflex. J Exp Psychol 55: 613-616.

Stiedl O, Misane I, Spiess J, Ogren SO (2000). Involvement of the 5$\mathrm{HT} 1 \mathrm{~A}$ receptors in classical fear conditioning in C57BL/6J mice. J Neurosci 20: 8515-27.

Walker DL, Davis M (1997). Double dissociation between the involvement of the bed nucleus of the stria terminalis and the central nucleus of the amygdala in startle increases produced by conditioned versus unconditioned fear. J Neurosci 17: 9375-83.

Walker DL, Davis M (2000). Involvement of NMDA receptors within the amygdala in short- versus long-term memory for fear conditioning as assessed with fear-potentiated startle. Behav Neurosci 114: 1019-33. 